\title{
Surgical Outcome of Thyroid Nodules with Atypia of Undetermined Significance and Follicular Lesion of Undetermined Significance in Fine Needle Aspiration Biopsy
}

\author{
${ }^{1}$ Saad Alqahtani, ${ }^{2}$ Saif Alsobhi, ${ }^{3}$ Riyadh I Alsalloum, ${ }^{4}$ Saleh N Najjar, ${ }^{5}$ Hindi N Al-Hindi
}

\begin{abstract}
Aim: To correlate selected clinical and ultrasonographic (US) characteristics with the final histopathological diagnosis in patients with atypia of undetermined significance (AUS) and follicular lesion of undetermined significance (FLUS), and whether this information can be used in planning the surgical approach.
\end{abstract}

Materials and methods: It is a retrospective study including the operated cases of AUS/FLUS from 2011 to 2014 treated at one center.

Results: This cohort included 87 women and 28 men. To test for independence between categorical variables, the chi-square test was used. There was no significant correlation between age or US variables and final pathological diagnosis. However, final diagnosis of malignancy was higher in men compared with women (64.3 and $41.4 \%$ respectively; $p=0.035)$. Furthermore, a significant association between the diagnosis of repeated fine needle aspiration biopsy (FNAB) and the final pathological diagnosis was noted (benign vs malignant, $p=0.005$ ).

Conclusion: The FNAB has a significant role in the assessment of thyroid nodules. Our results showed no correlation between age, US variables, and the risk of malignancy. Male gender is associated with higher risk of malignancy.

Clinical significance: Determining the risk of malignancy and prediction of surgical outcome may help triaging cases for repeat FNA or proceeding to surgery.

Keywords: Fine needle aspiration biopsy, Thyroid nodule, Ultrasound.

How to cite this article: Alqahtani S, Alsobhi S, Alsalloum RI, Najjar SN, Al-Hindi HN. Surgical Outcome of Thyroid Nodules with Atypia of Undetermined Significance and Follicular Lesion

${ }^{1}$ Assistant Professor, ${ }^{2}$ Professor, ${ }^{3}$ Fellow, ${ }^{4}$ Resident, ${ }^{5}$ Consultant ${ }^{1}$ Department of Surgery, College of Medicine, Majmaah University Majmaah, Kingdom of Saudi Arabia

${ }^{2}$ Department of Endocrine Surgery, King Faisal Specialist Hospital \& Research Center, Riyadh, Kingdom of Saudi Arabia

${ }^{3}$ Department of Radiology, King Faisal Specialist Hospital \& Research Center, Riyadh, Kingdom of Saudi Arabia

4,5 Department of Pathology, King Faisal Specialist Hospital \& Research Center, Riyadh, Kingdom of Saudi Arabia

Corresponding Author: Saad Alqahtani, Assistant Professor Department of Surgery, College of Medicine, Majmaah University Majmaah, Kingdom of Saudi Arabia, Phone: +966164042279 e-mail: drsaadalhabib@hotmail.com of Undetermined Significance in Fine Needle Aspiration Biopsy. World J Endoc Surg 2017;9(3):100-103.

Source of support: Nil

Conflict of interest: None

\section{INTRODUCTION}

Thyroid nodule is a common surgical problem. Although FNAB is an accurate diagnostic method for thyroid nodules, some of these FNABs are not diagnostic. The Bethesda System for Reporting Thyroid Cytopathology (BSRTC) has six categories, one of which is AUS or FLUS, which is a heterogeneous group that is difficult to classify as benign, follicular neoplasm, suspicious for malignancy, or malignant. ${ }^{1-6}$ In AUS/FLUS, the risk of malignancy in resected nodules is 5 to $15 \%$, but a variation from 6 to $48 \%$ is in record..$^{6-9}$

It has been reported that with repeated FNAB in AUS/ FLUS cases, about 56 to $68 \%$ will have a more definitive result and 15.6 to $48.6 \%$ will be interpreted as AUS/FLUS. ${ }^{7}$ The recommended management is clinical correlation and a repeat FNAB in 3 to 6 months. ${ }^{10}$ It has been recommended that if there is an indication for surgical intervention, it is not necessary to repeat the FNAB. ${ }^{4}$ Although it has been suggested that the usage of AUS/FLUS should not exceed $7 \%$ of thyroid FNABs, $3,7,9,10$ there is variation of this percentage from 3 to $29 \%$ across laboratories and from 2.5 to $28.6 \%$ among cytopathologists. ${ }^{5}$

Ultrasound findings can facilitate reaching a diagnosis of nodules with AUS/FLUS, ${ }^{11}$ although they may not differentiate benign from malignant nodules. ${ }^{7}$ As stated earlier, the aim of this study was to define any correlation between different clinical and US features with the final histopathology in patients with a diagnosis of AUS/FLUS, and if these data can be used in planning the surgical approach.

\section{MATERIALS AND METHODS}

This is a retrospective study approved by the Office of Research Affairs at King Faisal Specialist Hospital \& Research Center (KFSH\&RC). All FNABs that were 
diagnosed as AUS or FLUS between January 2011 and December 2014 were retrieved from the files of the Department of Pathology and Laboratory Medicine. All patients with primary thyroid nodules who subsequently underwent surgery were selected for this study. The patients' presenting and follow-up information were collected from the electronic medical records and pertinent missing data were extracted from the patients' charts.

Clinical data included age, gender, and affected lobe. All sonograms were reviewed by one radiologist for the following features: Size, content, echogenicity, shape, margins, presence of halo, echotexture, lymphadenopathy, vascularity, and calcifications. Final pathological diagnoses were obtained from the electronic medical records. Our target was the index nodules, and the incidental microcarcinomas were excluded. Statistical Package for the Social Sciences (SPSS), version 20, was used for data analysis.

\section{RESULTS}

A total of 2,229 thyroid FNABs of 1870 nodules from 1,624 patients were found between January 2011 and December 2014 at the KFSH\&RC, Riyadh, Kingdom of Saudi Arabia. Most biopsies (1774, 79.6\%) were done under in-house US guidance, 115 (5.2\%) were done by the pathologists in the FNA clinic, while the remaining 340 (15.2\%) were done at outside institutions (OSI), and slides were reviewed in our hospital as patients were referred for treatment. Among all FNABs, 305 (13.7\%) were diagnosed as AUS/FLUS; the rate of AUS/FLUS in our patients varied among the type of the specimen

Table 1: The distribution of FNAB diagnostic categories among procedure types

\begin{tabular}{|c|c|c|c|c|}
\hline $\begin{array}{l}\text { Diagnostic } \\
\text { category }\end{array}$ & $\begin{array}{l}\text { All } \\
n=2229 \\
(\%)\end{array}$ & $\begin{array}{l}\text { Clinic } \\
n=115 \\
(\%)\end{array}$ & $\begin{array}{l}\text { OSI } \\
n=340 \\
(\%)\end{array}$ & $\begin{array}{l}\text { US } \\
n=1774 \\
(\%)\end{array}$ \\
\hline Unsat & $168(7.5)$ & $25(21.7)$ & $44(12.9)$ & $99(5.6)$ \\
\hline Benign & $1283(57.6)$ & 62 (53.9) & $66(19.4)$ & $1155(65.1)$ \\
\hline AUS/FLUS & 305 (13.7) & $6(5.2)$ & $71(20.9)$ & 228 (12.9) \\
\hline FN/SFN & $78(3.5)$ & $2(1.7)$ & $19(5.6)$ & $57(3.2)$ \\
\hline SM & $92(4.1)$ & $6(5.2)$ & 27 (7.9) & 59 (3.3) \\
\hline Mal & $299(13.4)$ & $14(12.2)$ & $113(33.2)$ & $172(9.7)$ \\
\hline Other & $4(0.2)$ & 0 & 0 & $4(0.2)$ \\
\hline Total & $2,229(100)$ & $115(100)$ & $340(100)$ & $1,774(100)$ \\
\hline
\end{tabular}

Unsat: Unsatisfactory; SM: Suspicious for malignancy; FN/SFN: Follicular neoplasm/suspicious for follicular neoplasm source (Table 1), being highest in OSI (20.9\%) and least when done in the FNA clinic (5.2\%).

Totally, 305 nodules were diagnosed as AUS/FLUS, and $115(37.7 \%)$ of them underwent surgery. This group is the material of the present study. Among this group, $28(24.3 \%)$ are from male patients and 87 (75.7\%) nodules are from female patients (male:female, 1:3), with a mean age of 45.9 and 39.7 years respectively $(p=0.014)$. The nodules affected the right lobe in 63 (54.8\%), the left lobe in $48(41.7 \%)$, and the isthmus in 4 patients $(3.5 \%)$. The predilection to the right lobe is of specific note $(p=0.07)$. A final pathological diagnosis of malignancy was found in 18 male $(64.3 \%)$ and $36(41.4 \%)$ female subjects $(p=0.035)$. There was no association between patient age and risk of malignancy $(p=0.5)$.

The FNAB was repeated for 47 patients (40.9\%) under US guidance in our hospital prior to surgery. Table 2 depicts the distribution of final pathology among all patients who underwent surgery following the first or second FNAB. There was a significant relation between the result of second FNAB and the final pathology discriminating benign from malignant $(p=0.005)$ and nonneoplastic from neoplastic $(p=0.029)$ nodules (Table 3 ).

In-house preoperative US scan was available for 110 nodules. These were reexamined by a radiologist, and the results were similar to their original reports in almost all cases. Table 4 depicts the distribution of US findings. Our data show no significant correlation between US features and the final pathological diagnosis in AUS/ FLUS nodules.

\section{DISCUSSION}

In 2007, the National Cancer Institute (NCI) hosted the NCI Thyroid Fine Needle Aspiration State of the Science Conference. The BSRTC was proposed at that conference. The BSRTC has six diagnostic categories, one of which is AUS/ FLUS that is a new challenging diagnostic category. ${ }^{1,2,7}$

In our cohort, the rate of AUS/FLUS was $13.7 \%$, which is higher than the recommended range of less than $7 \%$. ${ }^{1}$ Since confounding factors contribute to the diagnosis of this category, which include air drying and obscuring blood clots, the rate is least when the procedure is performed by the pathologist where quick aspiration and immediate smear preparation are enhanced, and such a

Table 2: Final pathological diagnosis and number of AUS/FLUS diagnosis

\begin{tabular}{llllllll}
\hline & $\begin{array}{l}\text { Benign } \\
\text { (excl. FA) }\end{array}$ & $\begin{array}{l}\text { Follicular } \\
\text { adenoma }\end{array}$ & FTC & PTC & Lymphoma & $\begin{array}{l}\text { All neoplasms } \\
\text { (incl. FA) }\end{array}$ & $\begin{array}{l}\text { All } \\
\text { malignancies }\end{array}$ \\
\hline All cases $(\mathrm{n}=115)$ & $49(42.6 \%)$ & $12(10.4 \%)$ & $3(2.6 \%)$ & $49(42.6 \%)$ & $2(1.7 \%)$ & $66(57.3 \%)$ & $54(46.9 \%)$ \\
One time $(\mathrm{n}=68)$ & $33(48.5 \%)$ & $8(11.7 \%)$ & $1(1.5 \%)$ & $25(36.7 \%)$ & $1(1.5 \%)$ & $35(51.5 \%)$ & $27(39.7 \%)$ \\
Twice $(\mathrm{n}=47)$ & $16(34 \%)$ & $4(8.5 \%)$ & $2(4.3 \%)$ & $24(51 \%)$ & $1(2.1 \%)$ & $31(66 \%)$ & $27(57.4 \%)$ \\
\hline
\end{tabular}

FA: Follicular adenoma; FTC: Follicular thyroid carcinoma; PTC: Papillary thyroid carcinoma 
Table 3: Final pathology and second FNAB diagnosis

\begin{tabular}{lllll}
\hline \multirow{3}{*}{$\begin{array}{l}\text { Second } \\
\text { FNAB }\end{array}$} & $\begin{array}{l}\text { Benign } \\
\text { (excl. FA) }\end{array}$ & FA & Malignant (\%) \\
\hline Benign & 7 & 1 & 3 & $27.3 \%$ \\
AUS/FLUS & 7 & 3 & 10 & $50 \%$ \\
PTC/SPTC & 0 & 0 & 12 & $100 \%$ \\
SFN & 2 & 0 & 2 & $50 \%$ \\
Total & 16 & 4 & 27 & $57.4 \%$ \\
& Benign (benign +FA) & Malignant & $\mathrm{p}=0.005$ \\
& $(42.6 \%)$ & $(57.4 \%)$ & \\
& Non-neoplastic & Neoplastic (FA & $\mathrm{p}=0.029$ \\
& $(34 \%)$ & + malignancy) \\
& \multicolumn{5}{c}{$(66 \%)$} \\
\hline
\end{tabular}

Table 4: Ultrasound features of AUS/FLUS patients $(n=110)$

\begin{tabular}{|c|c|c|c|}
\hline Malignant & Benign & Feature & $p$-value \\
\hline Size & $32 \pm 20 \mathrm{~mm}$ & $30 \pm 22 \mathrm{~mm}$ & 0.574 \\
\hline Content & & & 0.693 \\
\hline Partially cystic & $3(4.9 \%)$ & $5(9.3 \%)$ & \\
\hline Partially solid & $16(26.2 \%)$ & $15(27.8 \%)$ & \\
\hline Solid & $40(65.6 \%)$ & $31(57.4 \%)$ & \\
\hline Echogenecity & & & 0.904 \\
\hline Hyperechoic & $18(29.5 \%)$ & $14(25.9 \%)$ & \\
\hline Hypoechoic & $31(50.8 \%)$ & $29(53.7 \%)$ & \\
\hline Isoechoic & $10(16.4 \%)$ & $8(14.8 \%)$ & \\
\hline Shape & & & 0.836 \\
\hline Irregular & $22(36.1 \%)$ & $19(35.2 \%)$ & \\
\hline Ovoid & $37(60.7 \%)$ & $32(59.3 \%)$ & \\
\hline Margins & & & 0.830 \\
\hline III-defined & $25(41 \%)$ & $21(38.9 \%)$ & \\
\hline Smooth & $34(55.7 \%)$ & $30(55.6 \%)$ & \\
\hline Halo & & & 0.276 \\
\hline No & $24(39.3 \%)$ & $28(51.9 \%)$ & \\
\hline Yes & $35(57.4 \%)$ & $23(42.6 . \%)$ & \\
\hline Echotexture & & & 0.450 \\
\hline Homogeneous & $27(44.3 \%)$ & $18(33.3 \%)$ & \\
\hline Heterogeneous & $32(52.5 \%)$ & $33(61.1 \%)$ & \\
\hline Lymphadenopathy & & & 0.818 \\
\hline No & $55(90.2 \%)$ & $47(87 \%)$ & \\
\hline Yes & $4(6.6 \%)$ & $4(7.4 \%)$ & \\
\hline Vascularity & & & 0.803 \\
\hline Hypovascular & $25(41 \%)$ & $23(42.6 \%)$ & \\
\hline Hypervascular & $34(55.7 \%)$ & $28(51.9 \%)$ & \\
\hline Calcification & & & 0.105 \\
\hline No & $51(83.6 \%)$ & $36(66.7 \%)$ & \\
\hline Yes & $8(13.1 \%)$ & $15(27.8 \%)$ & \\
\hline
\end{tabular}

procedure can only be done in a few cases with palpable solitary nodules. Cases coming from smaller institutions may suffer from both suboptimal aspiration techniques and smear preparation.

In our cohort, the risk of malignancy is higher in males $(p=0.035)$, but there was no correlation between the age and the risk of malignancy $(\mathrm{p}=0.496)$. Nagarkatti et al. also concluded that age and gender did not affect the decision for surgical intervention in AUS/FLUS patients. ${ }^{12}$ No difference between benign and malignant nodules or between the malignant nodules themselves after one or two AUS/FLUS diagnoses with regard to age and gender was reported by Park et al. ${ }^{7}$ Likewise, Teixeira et al found no statistically significant correlation between age and gender and risk of malignancy in patients with FLUS, and their conclusion supports the surgical intervention to obtain a diagnosis in this group. ${ }^{13}$ Younger patients and some US features contribute to an increase in the possibility for surgery in AUS/FLUS patients, while sex was not predictive based on univariate logistic regression analysis. ${ }^{14}$

Our findings showed the value of repeated FNAB and risk of malignancy in discriminating benign from malignant nodules $(p=0.005)$ and non-neoplastic from neoplastic nodules $(p=0.029)$. This will justify the continued surveillance in patients who otherwise do not have an indication for surgical intervention. Similar conclusions were made by Broome et $\mathrm{al}^{4}$ and Chen et al. ${ }^{6}$ The latter authors advised to repeat FNAB after 3 to 6 months, and if the repeated biopsy is nondiagnostic or again interpreted as AUS/FLUS, then surgery is indicated. On the contrary, some authors observed that no difference in malignancy rate between one and repeated FNABs. ${ }^{2,14}$ We found that the incidence of AUS/FLUS on repeated FNAB (42.5\%) is within the range of previously published data of 20 to $48.5 \%,{ }^{4,8,12,14}$ and that the risk of malignancy in two consecutive AUS/FLUS was $50 \%$, higher than most published data of 13.5 to $43 \%$. $4,7,8,14$

Our data support the significant benefit of repeating FNAB in triaging patients with AUS/FLUS; those who have a diagnosis of malignancy or follicular neoplasm/ suspicious for follicular neoplasm should undergo surgery. In our patients, the risk of malignancy in benign diagnoses after the second FNAB was $27.3 \%$, which is close to what was published by Vanderlaan (29\%). ${ }^{8}$

As stated earlier, our data show no significant association between US features and the final pathological diagnosis in AUS/FLUS nodules. It was previously reported that US features did not have a role in the decision for surgery, observation of the patient, or repeating FNAB in AUS/FLUS patients. ${ }^{12}$ On the contrary, there was no statistical difference between benign and malignant nodules or between malignancies after one and repeated FNABs in regard of nodule size or other US features as reported by Park et al. ${ }^{7}$ Furthermore, in patients diagnosed with FLUS, there was no statistically significant relation between risk of malignancy and the nodule size. ${ }^{13}$

It was concluded by Ho et $\mathrm{al}^{14}$ that increasing nodule size and hypervascularity were found helpful in triaging the patients for surgical intervention, while hypoechogenicity, infiltrative margins, and calcifications were not 
informative. Moreover, none of the above mentioned US characteristics or demographic features were significant on multivariable analysis. In a study by Çuhaci et $\mathrm{al}^{2}{ }^{2}$ it was found on multivariate logistic regression analysis that hypoechogenicity was the only predictive feature of malignancy in AUS patients and peripheral vascularition in the FLUS group. They concluded that in AUS/FLUS patients, the US characteristics alone were insufficient to predict the malignancy and, subsequently, the clinical features should be considered along with the US characteristics in the evaluation of thyroid nodules.

For patients with a single diagnosis of AUS/FLUS in our cohort, indications for surgery included compressive symptoms, worrisome features on US, retrosternal extension, failure of medical management in Graves' disease, increasing nodule size, clinical judgment, and patient preference.

\section{CONCLUSION AND CLINICAL SIGNIFICANCE}

The FNAB remains an important step in the evaluation of thyroid nodules. Our study showed no correlation between age, US features, and risk of malignancy in AUS/FLUS patients. Male patients, however, have higher risk of malignancy. More studies are needed to help in stratifying surgical decision for these thyroid nodules. Our study has the limitations of being retrospective studies and the fact that the sample number is relatively small. More preoperative investigational tools may in the future help in differentiating between benign and malignant nodules.

\section{ACKNOWLEDGMENT}

Authors would like to thank Mohamed Shoukri, PhD, National Biotechnology Center, Research Center, King Faisal Specialist Hospital, Kingdom of Saudi Arabia, for his valuable contribution and input.

\section{REFERENCES}

1. Cibas ES, Ali SZ. The Bethesda system for reporting thyroid cytopathology. Am J Clin Pathol 2009 Nov;132(5):658-665.

2. Çuhaci N, Arpaci D, Üçler R, Yazgan AK, Kıyak G, Yalçin S, Ersoy PE, Güler G, Ersoy R, Çakir B. Malignancy rate of thyroid nodules defined as follicular lesion of undetermined significance and atypia of undetermined significance in thyroid cytopathology and its relation with ultrasonographic features. Endocr Pathol 2014 Sep;25(3):248-256.

3. Dincer N, Balci S, Yazgan A, Guney G, Ersoy R, Cakir B, Guler G. Follow-up of atypia and follicular lesions of undetermined significance in thyroid fine needle aspiration cytology. Cytopathology 2013 Dec;24(6):385-390.

4. Broome J, Cate F, Solorzano C. Utilization and impact of repeat biopsy for follicular lesion/atypia of undetermined significance. World J Surg 2014 Mar;38(3):628-633.

5. Walts AE, Mirocha J, Bose S. Follicular lesion of undetermined significance in thyroid FNA revisited. Diagn Cytopathol 2014 Jan;42(1):18-22.

6. Chen JC, Pace SC, Khiyami A, McHenry CR. Should atypia of undetermined significance be subclassified to better estimate risk of thyroid cancer? Am J Surg 2014 Mar;207(3):331-336.

7. Park VY, Kim E-K, Kwak JY, Yoon JH, Moon HJ. Malignancy risk and characteristics of thyroid nodules with two consecutive results of atypia of undetermined significance or follicular lesion of undetermined significance on cytology. Eur Radiol 2015 Sep;25(9):2601-2607.

8. VanderLaan PA, Marqusee E, Krane JF. Clinical outcome for atypia of undetermined significance in thyroid fine-needle aspirations. Am J Clin Pathol 2011;135(5):770-775.

9. Singh RS, Wang HH. Eliminating the "atypia of undetermined significance/follicular lesion of undetermined significance" category from the Bethesda System for Reporting Thyroid Cytopathology. Am J Clin Pathol 2011 Dec;136(6):896-902.

10. Chen JC, Pace SC, Chen BA, Khiyami A, McHenry CR. Yield of repeat fine-needle aspiration biopsy and rate of malignancy in patients with atypia or follicular lesion of undetermined significance: the impact of the Bethesda System for Reporting Thyroid Cytopathology. Surgery 2012 Dec;152(6):1037-1044.

11. Yoo WS, Choi HS, Cho SW, Moon JH, Kim KW, Park HJ, Park SY, Choi SI, Choi SH, Lim S, et al. The role of ultrasound findings in the management of thyroid nodules with atypia or follicular lesions of undetermined significance. Clin Endocrinol 2014 May;80(5):735-742.

12. NagarkattiSS, Faquin WC, Lubitz CC, Garcia DM, Barbesino G, Ross DS, Hodin RA, Daniels GH, Parangi S. Management of thyroid nodules with atypical cytology on fine-needle aspiration biopsy. Ann Surg Oncol 2013 Jan;20(1):60-65.

13. Teixeira GV, Chikota H, Teixeira T, Manfro G, PaiSI, Tufano RP. Incidence of malignancy in thyroid nodules determined to be follicular lesions of undetermined significance on fine-needle aspiration. World J Surg 2012 Jan;36(1):69-74.

14. Ho AS, Sarti EE, Jain KS, Wang H, Nixon IJ, Shaha AR, et al. Malignancy rate in thyroid nodules classified as Bethesda category III (AUS/FLUS). Thyroid 2014 May;24(5):832-839. 